\title{
Otimização da técnica de PCR para a detecção de Xanthomonas axonopodis pv. phaseoli em sementes de feijão*
}

\author{
Franklin Cordeiro Silva ${ }^{1}$, Ricardo Magela de Souza ${ }^{1}$, Ana Beatriz Zacaroni ${ }^{1}$, Flávia Mara Vieira Lelis ${ }^{1}$ \& Antonia dos \\ Reis Figueira ${ }^{1}$
}

${ }^{1}$ Universidade Federal de Lavras (UFLA), Departamento de Fitopatologia, Caixa Postal 3037, 37200-000, Lavras, MG. *Parte da Dissertação de Mestrado do primeiro autor.

Autor para correspondência: Ricardo Magela de Souza (rmagelas@dfp.ufla.br)

Data de chegada: 06/11/2012. Aceito para publicação em: 15/01/2013.

1746

\section{RESUMO}

Silva, F.C., Souza, R.M., Zacaroni, A.B., Lelis, F.M.V., Figueira, A.R. Otimização da técnica de PCR para a detecção de Xanthomonas axonopodis pv. phaseoli em sementes de feijão. Summa Phytopathologica, v.39, n.1, p.45-50, 2013.

O crestamento bacteriano comum, causado por Xanthomonas axonopodis pv. phaseoli (Xap), é a principal bacteriose do feijoeiro no Brasil, sendo transmitida principalmente por sementes. O presente trabalho teve como objetivo aperfeiçoar uma técnica, por meio de diferentes métodos de preparação do extrato, para a detecção de Xap, bem como sua deteç̧ão simultânea com Curtobacterium flaccumfaciens pv. flaccumfaciens (Cff) nos extratos de sementes de feijão,via PCR. A partir de amostras de sementes de feijão inoculadas artificialmente com Xap e lotes comerciais, foram avaliados: extrato bruto obtido diretamente das sementes, extrato concentrado por filtração em membrana de $0,22 \mu \mathrm{M}$ de diâmetro, extrato concentrado por centrifugação e extrato plaqueado em meio semi-seletivo XCP1 com e sem antibióticos (BIO-PCR). Avaliou-se a presença simultânea de Xap e Cff em 10 lotes comerciais de sementes de feijão através da reação multiplex, utilizandos-se os primers X4c, X4e, CffFOR2 e CffREV4. A partir do extrato bruto, do extrato concentrado por centrifugação e por filtragem em membrana Millipore ${ }^{\circledR}$ não foi possível a deteç̧ão de Xap nas sementes de feijão artificialmente contaminadas nem nos 47 lotes comerciais de sementes/ grãos de feijão. A técnica de BIO-PCR permitiu a detecção de Xap a partir de extratos de sementes de feijão artificialmente contaminadas e em 18 dos 47 lotes comerciais. A técnica de deteç̧ão simultânea de Xap e Cff no mesmo gel é viável, por amplificar fragmentos de DNA típicos de cada fitobactéria. $\mathrm{O}$ uso do meio de cultura XCP1 sem adição de antibióticos permitiu detectar Xap com período de incubação menor em um dia em comparação à detecção utilizando-se o meio de cultura com antibióticos

Palavras-chave adicionais: Crestamento Bacteriano Comum, Curtobacterium flaccumfaciens pv. flaccumfaciens, lotes comerciais, detecção.

\section{ABSTRACT}

Silva, F.C., Souza, R.M., Zacaroni, A.B., Lelis, F.M.V., Figueira, A.R. Optimization of PCR technique for detection of Xanthomonas axonopodis pv. phaseoli in bean seeds. Summa Phytopathologica, v.39, n.1, p.45-50, 2013.

Common bacterial blight, caused by Xanthomonas axonopodis pv. phaseoli (Xap), is the major bacteriosis affecting bean plants in Brazil and is mainly transmitted by seeds. This study aimed to improve a technique, using different methods of extract preparation, for the detection of Xap alone and simultaneously with Curtobacterium flaccumfaciens pv. flaccumfaciens (Cff) in bean seed extracts, via PCR. Samples of bean seeds artificially inoculated with Xap and commercial batches were used to evaluate: crude extract obtained directly from the seeds, extract concentrated by filtration in $0.22 \mathrm{iM}$-diameter membrane, extract concentrated by centrifugation and extract plated on semiselective XCP1 medium with and without antibiotics (BIO-PCR). The simultaneous presence of Xap and Cff in 10 commercial batches of bean seeds was assessed through multiplex reaction, using the primers $\mathrm{X} 4 \mathrm{c}$, $\mathrm{X} 4 \mathrm{e}$, and CffFOR2 CffREV4. By using crude extract, extract concentrated by centrifugation and by filtration in millipore ${ }^{\circledR}$ membrane, detection of Xap in bean seeds artificially contaminated or in 47 commercial batches of bean seeds/grains was not possible. BIO-PCR technique allowed the detection of Xap in extracts from artificially contaminated bean seeds and in 18 of the 47 commercials batches. The technique of simultaneous detection of Xap and Cff on the same gel is feasible, for amplifying DNA fragments typical of each phytobacterium. The use of XCP1 culture medium without adding antibiotics allowed the detection of Xap with shorter incubation period in one day, compared to detection using the culture medium with antibiotics.

Additional keywords: Common Bacterial Blight, Curtobacterium flaccumfaciens pv. flaccumfaciens, commercial batches, detection.

Um dos fatores que contribuem para o baixo rendimento da cultura do feijoeiro é a utilização de grãos, em vez de sementes, para o plantio, sendo que no Brasil, a taxa de utilização de semente comercial de feijoeiro é muito baixa, em torno de $8 \%$ (14). A qualidade sanitária da semente do feijoeiro é um dos fatores mais importantes para o sucesso da produção, pois muitas doenças da cultura que levam à baixa produtividade são transmissíveis pelas sementes (4). As medidas de controle das doenças do feijoeiro, para serem eficientes, devem 
contemplar ações associadas de controle integrado, como utilização de sementes sadias e tratamento químico de sementes (18).

O crestamento bacteriano comum, causado por Xanthomonas axonopodis pv. phaseoli (Smith 1897) Vauterin, Hoste, Kersters \& Swinger (1995) (Xap) tem sido problema nos estados de São Paulo, Minas Gerais, Paraná, Santa Catarina, Espírito Santo, Rio Grande do Sul e na região Centro-Oeste, principalmente na safra das águas, caracterizando-se como a principal bacteriose do feijoeiro no Brasil (2). Além dessa, a murcha-de-curtubacterium, causada por Curtobacterium flaccumfaciens pv. flaccumfaciens (Cff) $(5,7,8)$, embora detectada no Brasil em 1997 (13), tem trazido grande preocupação aos pesquisadores e produtores. Essas duas bacterioses têm nas sementes contaminadas suas principais formas de disseminação. O constante uso de sementes contaminadas tem sido a causa do aumento do nível de inóculo de bacterioses nos campos de produção (2).

Vários são os métodos de detecção de bactérias em sementes. Porém, análises de diagnose, para fins de subsidiar a adoção de tecnologias preventivas à ocorrência de epidemias, requerem a combinação, em série, de inúmeras técnicas, envolvendo desde a inspeção visual da semente até o emprego de técnicas moleculares para a identificação e quantificação da bactéria (16). Em certos casos, a fitobactéria encontra-se associada às sementes, sem que se possa perceber sua presença, em razão da ausência de sintomas externos visualmente reconhecíveis (17). Assim sendo, inspeções de campo nem sempre são suficientemente seguras para detectar o crestamento bacteriano comum, tornando-se necessária a detecção do patógeno por meio de testes de laboratório (16).

Neste contexto, técnicas moleculares em procedimentos rotineiros de detecção de patógenos vêm sendo cada vez mais estudadas como ferramentas promissoras, devido à sua maior precisão em caracterizar organismos e apresentar resultados rápidos no processo de identificação (12). Os marcadores moleculares baseados na análise do DNA não são afetados pelo ambiente, permitindo uma análise mais objetiva e precisa. As técnicas envolvendo o DNA apresentam alto poder de resolução e, como as diferenças nas seqüências de nucleotídeos ao longo da fita de DNA de indivíduos distintos são extremamente abundantes, a distinção se torna mais fácil, na maioria dos casos (3).

Dentre as técnicas moleculares, a BIO-PCR, que consiste em deixar as sementes em uma solução extratora por períodos variáveis seguida de submissão do sobrenadante ao plaqueamento em meio semi-seletivo e as colônias obtidas à reação da polimerase em cadeia (PCR), utilizando primers com alta especificidade e que forneçam resultados confiáveis (15) tem se destacado na detecção de bactérias em sementes. Nestes casos, procura-se trabalhar com extratos das sementes, partindo-se da premissa de que sendo impossível encontrar uma semente infectada ou infestada no lote, procura-se a fitobactéria no lote inteiro (17). Além de serem rápidas, sensíveis e específicas, as técnicas moleculares permitem economia de tempo e redução de custos na identificação de patógenos. Em laboratórios de análises de sementes, a técnica da PCR tem sido muito usada, possibilitando a detecção e o diagnóstico de algumas bactérias, inclusive Xap.

O objetivo deste trabalho foi aperfeiçoar uma técnica para a detecção de Xanthomonas axonopodis pv. phaseoli, em sementes de feijão; verificar a sua presença em lotes comerciais, por meio de diferentes formas de preparação do extrato, e detectar simultaneamente com Curtobacterium flaccumfaciens pv. flaccumfaciens.

\section{MATERIAL E MÉTODOS}

Os trabalhos foram conduzidos nos Laboratórios de Bacteriologia de Plantas e Virologia Vegetal do Departamento de Fitopatologia da Universidade Federal de Lavras (UFLA).

\section{Experimento 1}

Origem, isolamento, purificação e preservação do patógeno

$\mathrm{O}$ isolado de Xap obtido de folhas de feijoeiro provenientes da região produtora de Minas Gerais se encontra preservado em peptona glicerol a $-80^{\circ} \mathrm{C}$ (11) e em folhas herborizadas. Para o uso experimental, o isolado foi transferido para o meio 523 (9) pelo método de estrias paralelas e incubado por 48 horas a $28^{\circ} \mathrm{C}$.

\section{Origem das sementes de feijão}

Foram utilizadas amostras de sementes básicas da cultivar Pérola, as quais se encontravam armazenadas em câmara fria $\left(10^{\circ} \mathrm{C}\right.$ e $50 \%$ UR), no Laboratório de Patologia de Sementes da UFLA. Foram analisadas amostras de 1.000 sementes. $\mathrm{O}$ tratamento 1 consistiu de 1.000 sementes sadias; o tratamento 2, de 1 semente inoculada artificialmente com Xap, em 999 sadias e o tratamento 3, com 2 sementes inoculadas artificialmente com Xap, em 998 sadias. Todos os tratamentos foram realizados em triplicatas.

\section{Inoculação das sementes}

A inoculação das sementes de feijão foi feita pela técnica de restrição hídrica, adequada para aumentar a eficiência do processo de inoculação de Xap em sementes de feijão (10). Inicialmente as sementes foram desinfestadas superficialmente em solução de hipoclorito de sódio $(\mathrm{NaOCl} 0,5 \%)$ por 2 minutos, lavadas por três vezes em água destilada esterilizada e secas sobre papel filtro em câmara de fluxo laminar, por 1 hora. A seguir foram colocadas 20 sementes desinfestadas em cada placa de Petri de $9 \mathrm{~cm}$ de diâmetro, contendo $30 \mathrm{~mL}$ de meio de cultura 523 (9) acrescidos de 66,10g de manitol, para se atingir o potencial hídrico - 0,95 MPa (Mega Pascal), sob o qual Xap fora cultivada por 24 horas a $28^{\circ} \mathrm{C}$. As placas foram levemente agitadas e guardadas em câmara de crescimento por 48 horas.

\section{Origem dos lotes comerciais de sementes e grãos de feijão}

Utilizaram-se amostras de 47 lotes comerciais de sementes de feijão e também grãos, de diversas regiões do país (Tabela 1). Algumas amostras se encontravam armazenadas em câmara fria e seca $\left(10^{\circ} \mathrm{C}\right.$ e $50 \%$ UR), no Laboratório de Patologia de Sementes da UFLA. Outras foram cedidas por pesquisadores de outras instituições ou adquiridas no comércio. As amostras foram compostas por 1.000 sementes e os ensaios realizados em triplicatas.

\section{Preparo dos extratos brutos de sementes de feijão}

Utilizaram-se sementes da cultivar Pérola, inoculadas artificialmente pelo método de condicionamento fisiológico e amostras de 47 lotes comerciais de sementes e/ou grãos de feijão. Amostras de 1.000 sementes de feijão foram imersas em $600 \mathrm{~mL}$ de água destilada e esterilizada, permanecendo, aproximadamente, 18 horas à temperatura de $4^{\circ} \mathrm{C}$. Após o período de incubação foram obtidos os extratos brutos de sementes.

\section{Extrato bruto de sementes}

Alíquotas de $5 \mu \mathrm{L}$ dos extratos brutos de sementes foram retiradas e adicionadas diretamente aos tubos de reação para a amplificação por PCR. 
Tabela 1. Procedência dos lotes comerciais de sementes e grãos de feijão analisados quanto à presença de Xanthomonas axonopodis pv. phaseoli.

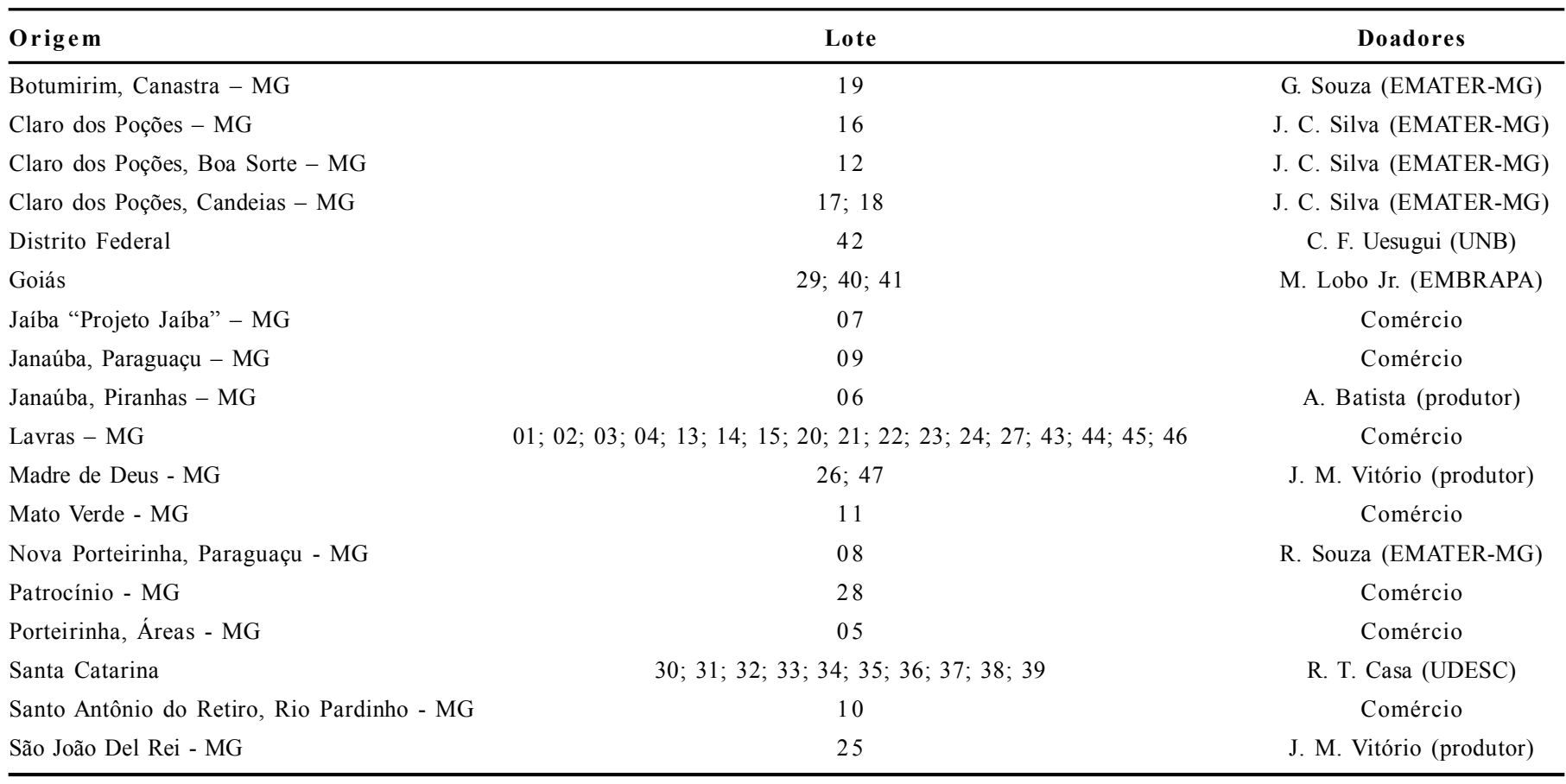

Extrato concentrado por filtração em membrana Millipore ${ }^{\circledR}$

Alíquotas de $100 \mathrm{~mL}$ dos extratos brutos foram submetidas à filtração em membrana Millipore ${ }^{\circledR}(0,22 \mu \mathrm{M}$ de diâmetro de poro). A seguir as membranas permaneceram imersas em $5 \mathrm{~mL}$ de água ultrapura por 1 hora, a $28^{\circ} \mathrm{C}$, sob agitação constante, para a recuperação das células bacterianas. Cinco $\mu \mathrm{L}$ da suspensão obtida foram então adicionados aos tubos de reação para a amplificação por PCR.

\section{Extrato concentrado por centrifugação}

Cento e cinco $\mathrm{mL}$ de extrato bruto foram centrifugados a $30.000 \mathrm{~g}$, por 30 minutos. Os sedimentos foram ressuspendidos em $3 \mathrm{~mL}$ de água ultrapura esterelizada e $5 \mu \mathrm{L}$ adicionados aos tubos de reação para a amplificação por PCR.

\section{BIO-PCR}

Alíquotas de $500 \mu \mathrm{L}$ de extrato bruto foram diluídas em solução salina estéril $(\mathrm{NaCl} 0,85 \%)$, nas concentrações de $10^{-1}$ a $10^{-4}$, sendo $100 \mu \mathrm{L}$ das diluições $10^{-2}$ e $10^{-4}$ plaqueados em meio de cultura XCP1 (10 $\mathrm{g}$ de peptona; $10 \mathrm{~g}$ de brometo de potássio; $0,25 \mathrm{~g}$ de cloreto de cálcio; $15 \mathrm{~g}$ de agar; $10 \mathrm{~g}$ de amido solúvel; $0,15 \mathrm{~mL}$ de cristal violeta $\mathrm{e}$ $1 \mathrm{~L}$ de água destilada; após autoclavagem foram adicionados $50 \mathrm{mg} / \mathrm{L}$ cefalexina; $10 \mathrm{mg} / \mathrm{L}$ fluorouracil; $0,4 \mathrm{mg} / \mathrm{L}$ tobramicina; $10 \mathrm{~mL}$ de Tween ${ }^{\circledR}$ 80 e $50 \mathrm{mg} / \mathrm{L}$ ciclohexamina) (21) e XCP1 sem adição dos antibióticos. As placas foram incubadas, por 72 horas, a $28^{\circ} \mathrm{C}$, em câmara de crescimento.

Após o período de incubação, foram adicionados às placas $3 \mathrm{~mL}$ de água ultrapura esterelizada e das suspensões bacterianas obtidas foram retirados $5 \mu \mathrm{L}$ e adicionados aos tubos de reação para a amplificação por PCR.

\section{Reação de amplificação}

As reações de amplificação de DNA foram realizadas em volume de $50 \mu \mathrm{L}$, sendo $5 \mu \mathrm{L}$ de tampão $10 \mathrm{X} ; 3 \mu \mathrm{L}$ de $\mathrm{MgCl}_{2}, 1 \mu \mathrm{L}$ de dNTP's; 1 $\mu \mathrm{L}$ de cada primer X4c (5'-GGCAACACCCGATCCCTAAAACAGG3') e X4e (5'-CGCCGGAAGCACGATCCTCGAAG-3') (1); 0,5 $\mu \mathrm{L}$ de Taq DNA polimerase $(5 \mathrm{U} / \mu \mathrm{L}) ; 5 \mu \mathrm{L}$ da suspensão bacteriana e 33,5 $\mu \mathrm{L}$ de água ultrapura.

Utilizou-se, como controles, suspensão de Xap e água ultrapura. O ciclo utilizado foi desnaturação inicial a $94{ }^{\circ} \mathrm{C} / 2$ minutos, 25 ciclos de $94{ }^{\circ} \mathrm{C} / 1$ minuto, $58{ }^{\circ} \mathrm{C} / 1$ minuto, $72{ }^{\circ} \mathrm{C} / 2$ minutos e extensão final a $72{ }^{\circ} \mathrm{C} / 8$ minutos (20 modificado).

\section{Eletroforese e fotodocumentação}

Após a reação no termociclador, $5 \mu \mathrm{L}$ das amostras acrescidas de $4 \mu \mathrm{L}$ do corante azul de bromofenol, foram colocados em gel de agarose $1 \%$ preparado com tampão Tris-Borato EDTA (TBE) $0,5 \mathrm{X}$, com corante fluorescente para ácidos nucléicos em água (Uniscience do Brasil) e submetidos à eletroforese. A fotodocumentação do gel foi realizada usando o programa de captura de imagens LisCap Version 2.0 .

\section{Experimento 2}

Detecção simultânea de Xanthomonas axonopodis pv. phaseoli e Curtobacterium flaccumfaciens pv. flaccumfaciens em lotes comerciais de sementes

Com o objetivo de se detectar simultaneamente a presença de Xap e Cff em suspensões bacterianas advindas da BIO-PCR de 10 lotes comerciais de sementes de feijão, utilizou-se a técnica multiplex. Testes anteriores indicaram a presença de Xap e Cff nos lotes 29, 36, 38, 40, 41 e 47, Cff no lote 42, lotes 33 e 34 com Xap e o lote 32 com ausência das duas bactérias. Também foram plaqueados $50 \mu \mathrm{L}$ de suspensão bacteriana de Xap $+50 \mu \mathrm{L}$ suspensão bacteriana de Cff como testemunhas positivas.

\section{Reação de amplificação}

As reações de amplificação de DNA foram realizadas em volume de $50 \mu \mathrm{L}$, sendo $5 \mu \mathrm{L}$ de tampão $10 \mathrm{X} ; 3 \mu \mathrm{L}$ de $\mathrm{MgCl}_{2} ; 1 \mu \mathrm{L}$ de dNTP's; 1 $\mu \mathrm{L}$ de cada primer; $0,5 \mathrm{U} / \mu \mathrm{L}$ de Taq DNA polimerase $(5 \mathrm{U} / \mu \mathrm{L}) ; 5 \mu \mathrm{L}$ da suspensão bacteriana e $31,5 \mu \mathrm{L}$ de água ultrapura.

Os dois pares de primers X4c e X4e (1) e CffFOR2 (5' 
GTTATGAACT TCACTCC

3')

CffREV 4

$\left(5^{\prime}\right.$

GATGTTCCCGGTGTTCAG 3') (22) foram adicionados ao mix da reação de PCR, para a detecção simultânea no mesmo gel de Xap e Cff.

As condições da reação foram: 1 ciclo de $94{ }^{\circ} \mathrm{C} / 2$ minutos, 25 ciclos de $94{ }^{\circ} \mathrm{C} / 1$ minuto, $58{ }^{\circ} \mathrm{C} / 1$ minuto, $72{ }^{\circ} \mathrm{C} / 2$ minutos e extensão final a $72^{\circ} \mathrm{C} / 8$ minutos (20 modificado).

\section{RESULTADOS E DISCUSSÃO}

\section{Experimento 1 \\ Deteç̧ão de Xap em extratos de sementes artificialmente inoculadas}

Seguindo o protocolo descrito na literatura (10) e utilizando-se os primers $\mathrm{X} 4 \mathrm{c}$ e X4e, fragmentos específicos de DNA com 730 pb foram amplificados.

A utilização do extrato bruto não permitiu a detecção de Xap, independente do tratamento utilizado (Figura 1), possivelmente pela presença de inibidores de PCR. De forma semelhante outros autores (20), ao realizarem estudos para detectar a bactéria Pseudomonas syringae pv. phaseolicola diretamente do extrato de sementes, não obtiveram êxito nas análises.

A presença de Xap em extratos resultantes da lavagem e agitação das membranas Millipore ${ }^{\circledR}$ utilizadas na filtração do extrato bruto não foi detectada por PCR (Figura 1).

$\mathrm{O}$ extrato concentrado por centrifugação também não apresentou resultado positivo para detecção de Xap (Figura 1). Resultados diferentes foram obtidos por Deuner et al. (6), em que a concentração do extrato de sementes artificialmente inoculadas por centrifugação permitiu a detecção de Curtobacterium flaccumfaciens pv. flaccumfaciens por meio da PCR.

A técnica de BIO-PCR permitiu a detecção de Xap em todos os extratos, inclusive no extrato sem adição de semente inoculada, o que indica a presença de Xap nas sementes de feijão consideradas sadias (Figura 1).
A presença de Xap variante fuscans em folhas de feijoeiro infectadas 10 dias antes dos sintomas da doença se tornarem visíveis foi constatada (23), comprovando, dessa forma, a eficiência da PCR.

A deteç̧ão de até uma colônia bacteriana de Xap por placa de Petri contendo meio seletivo foi verificada, quando se buscou a otimização da BIO-PCR para a sua detecção em sementes de feijão (10). Diversos trabalhos confirmam a sensibilidade e a eficiência da BIO-PCR para outras bactérias em sementes de feijão, como Pseudomonas syringae pv. phaseolicola (20) e Curtobacterium flaccumfaciens pv. flaccumfaciens (6), e em outras culturas, como a batata, em que foi possível detectar a presença de Clavibacter michiganensis subsp. sepedonicus (19).

Relatos na literatura (19) afirmam que a técnica de BIO-PCR possui muitas vantagens comparada aos métodos padrões para PCR, principalmente para a detecção de patógenos em sementes em análises de rotina. Dentre as vantagens, pode-se destacar a simplicidade da técnica, o aumento da sensibilidade e a detecção somente de células vivas. Dessa forma, por meio da BIO-PCR elimina-se a possibilidade de falsos positivos resultantes da presença de células mortas associadas às sementes e de falsos negativos, devido à eliminação de inibidores da PCR presentes em extratos de sementes e à multiplicação do patógeno, aumentando a sensibilidade de deteç̧ão.

Dentre as diferentes formas de preparação dos extratos de sementes de feijão para a detecção de Xap, verificou-se que os extratos obtidos a partir da ressuspensão das colônias bacterianas em meio semi-seletivo foram os mais promissores, podendo-se inferir que a BIO-PCR é uma técnica útil na detecção de Xap em análises de rotina de sementes de feijão.

\section{Detecção de Xap nos lotes comerciais de sementes e grãos de feijão}

A presença de Xap foi detectada em 18 lotes comerciais de sementes/ grãos dos 47 lotes avaliados. Dentre as diferentes formas utilizadas de preparação dos extratos, verificaram-se amplificações apenas para BIO-PCR.

O uso do meio de cultura XCP1 sem adição de antibióticos,

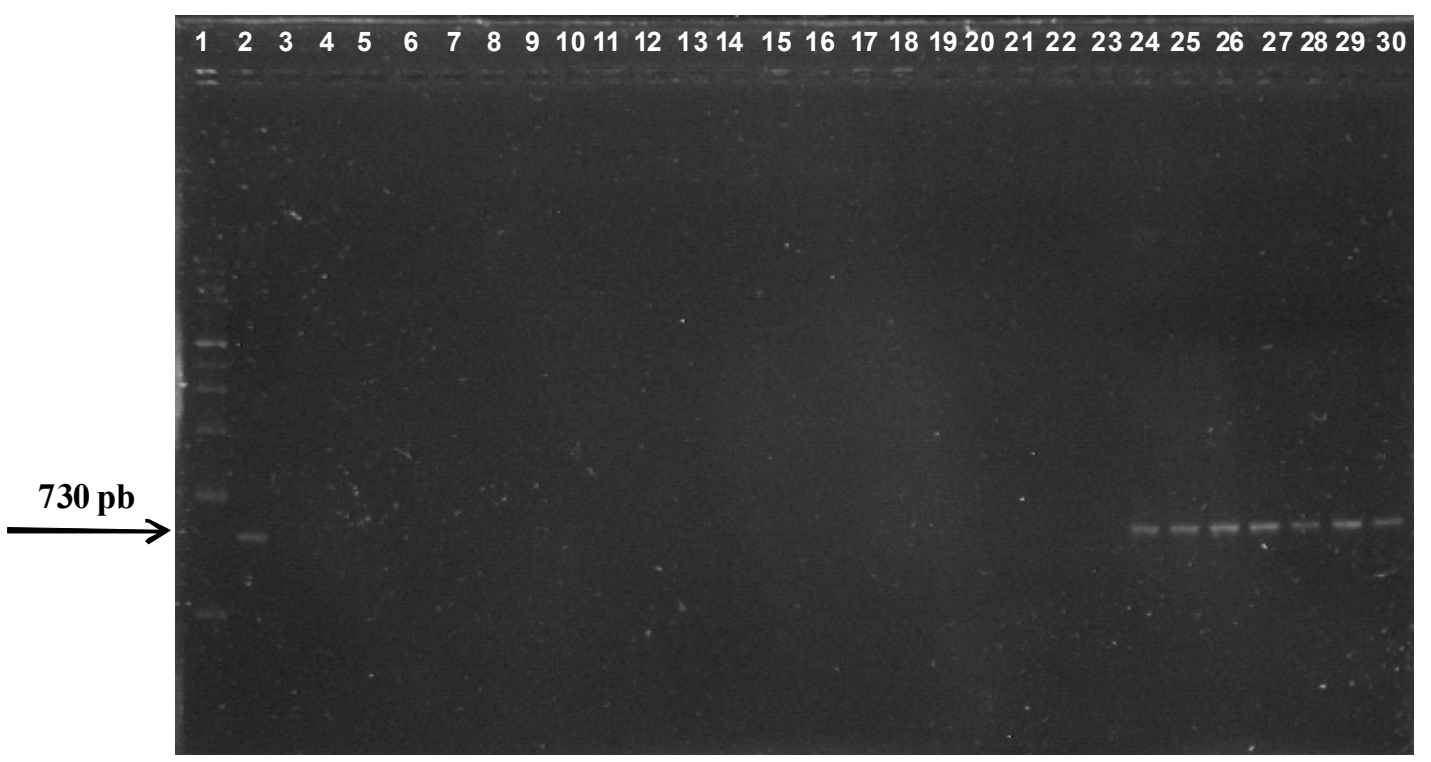

Figura 1. Análise eletroforética em gel de agarose (1\%) de $5 \mu \mathrm{L}$ dos produtos amplificados a partir dos extratos de sementes de feijão obtidos por diferentes métodos; 1 marcador de DNA (Jena Bioscience); 2 Xap; $3(0: 1000)^{1}$ eb; 4, 5, $6(1: 1000)^{2}$ eb; 7, 8, $9(2: 1000)^{3}$ eb; 10 $(0: 1000)$ ef; 11, 12, 13 (1:1000) ef; 14, 15, 16 (2:1000) ef; 17 (0:1000) ec; 18, 19, 20 (1:1000) ec; 21, 22, 23 (2:1000) ec; 24, 25, 26 (1:1000) Bio PCR; 27, 28, 29 (2:1000) Bio PCR; $30(0: 1000)$ Bio PCR. ${ }^{1}(0: 1000)=1000$ sementes sadias; ${ }^{2}(1: 1000)=1$ semente contaminada em 999 sadias; ${ }^{3}(2: 1000)=2$ sementes contaminadas em 998 sementes sadias, eb $=$ extrato bruto, ef $=$ extrato filtrado em Milipore $^{\circledR}$, ec $=$ extrato centrifugado. 
permitiu que Xap fosse detectada em maior número de lotes e com período de incubação menor em um dia em comparação à detecção utilizando-se meio de cultura com antibióticos (Tabela 2), aumentando

Tabela 2. Contagem do número de colônias suspeitas de Xanthomonas axonopodis pv phaseoli e saprófitas em meio de cultura XCP1 com e sem antibióticos, em 10 lotes comerciais de sementes de feijão, após 72 horas de incubação.

\begin{tabular}{|c|c|c|c|c|c|}
\hline \multirow{2}{*}{ Lotes } & \multirow{2}{*}{ Diluições } & \multicolumn{2}{|c|}{ Com antibiótico } & \multicolumn{2}{|c|}{ Sem antibiótico } \\
\hline & & $\begin{array}{l}\text { Colônias } \\
\text { suspeitas }\end{array}$ & $\begin{array}{l}\text { Colônias } \\
\text { saprófitas }\end{array}$ & $\begin{array}{l}\text { Colônias } \\
\text { suspeitas }\end{array}$ & $\begin{array}{l}\text { Colônias } \\
\text { saprófitas }\end{array}$ \\
\hline 29 & $10^{-2}$ & 1 & 33 & 6 & 15 \\
\hline 29 & $10^{-4}$ & - & 51 & 1 & 12 \\
\hline 32 & $10^{-2}$ & - & - & - & 7 \\
\hline 32 & $10^{-4}$ & - & 1 & - & 1 \\
\hline 33 & $10^{-2}$ & 3 & 36 & 6 & $>300$ \\
\hline 33 & $10^{-4}$ & 1 & 6 & - & 10 \\
\hline 34 & $10^{-2}$ & 4 & 1 & 8 & 29 \\
\hline 34 & $10^{-4}$ & - & - & - & - \\
\hline 36 & $10^{-2}$ & - & $>300$ & 47 & $>300$ \\
\hline 36 & $10^{-4}$ & 4 & $>300$ & 7 & $>300$ \\
\hline 38 & $10^{-2}$ & 3 & $>150$ & 18 & 170 \\
\hline 38 & $10^{-4}$ & - & - & - & 3 \\
\hline 40 & $10^{-2}$ & 3 & 16 & 7 & $>300$ \\
\hline 40 & $10^{-4}$ & - & - & 1 & 1 \\
\hline 41 & $10^{-2}$ & 15 & 111 & 8 & $>300$ \\
\hline 41 & $10^{-4}$ & 3 & 2 & - & 8 \\
\hline 42 & $10^{-2}$ & - & $>150$ & - & $>300$ \\
\hline 42 & $10^{-4}$ & - & - & - & 18 \\
\hline 47 & $10^{-2}$ & 138 & $>300$ & $>300$ & $>300$ \\
\hline 47 & $10^{-4}$ & 15 & 56 & 5 & 163 \\
\hline Testem & nha $10^{-2}$ & - & $>300$ & $>300$ & - \\
\hline Testem & nha $10^{-4}$ & - & $>300$ & $>300$ & - \\
\hline
\end{tabular}

assim a sensibilidade do método.

Embora o crescimento de colônias suspeitas e saprófitas tenha sido maior em meio de cultura sem antibióticos, a redução de um dia no período de incubação permitiu diminuir a quantidade de DNA na suspensão, evitando-se assim, falsos negativos.

Após 48 horas de incubação, as colônias plaqueadas em meio de cultura XCP1 sem antibióticos já apresentavam crescimento suficiente para a obtenção da suspensão para a PCR.

De 47 lotes comerciais de sementes/grãos de feijão analisados foi detectada a presença de Xap pela técnica de BIO-PCR (meio XCP1 com e sem adição de antibióticos) em 18 deles.

A utilização dos extratos de sementes bruto e concentrados por centrifugação e filtração em membrana Milipore ${ }^{\circledR}$ não permitiu a detecção de Xap. Provavelmente, a presença de inibidores da PCR no extrato bruto e a baixa concentração das células bacterianas, mesmo após a centrifugação e filtração em membrana, contribuiram para o resultado negativo. Contudo, novos estudos devem ser feitos visando superar esses problemas, como, por exemplo, aumentar o tempo de agitação das membranas em tampão após as filtrações, visando aumentar a possibilidade de liberação das células bacterianas. A extração das bactérias em meio enriquecido com peptona também é uma opção a ser investigada.

Experimento 2

Detecção simultânea de Xanthomonas axonopodis pv. phaseoli e Curtobacterium flaccumfaciens pv. flaccumfaciens, em lotes comerciais de sementes

A técnica de BIO-PCR utilizando dois pares de primers específicos numa reação multiplex permitiu confirmar a prévia detecção dos 10 lotes comerciais de sementes de feijão (Figura 2). Observaram-se amplificações dos fragmentos de DNA típicos a cada fitobactéria, 730 pb (Xap) e 306 pb (Cff), evidenciando assim que a técnica multiplex pode ser utilizada na detecção simultânea de Xap + Cff.

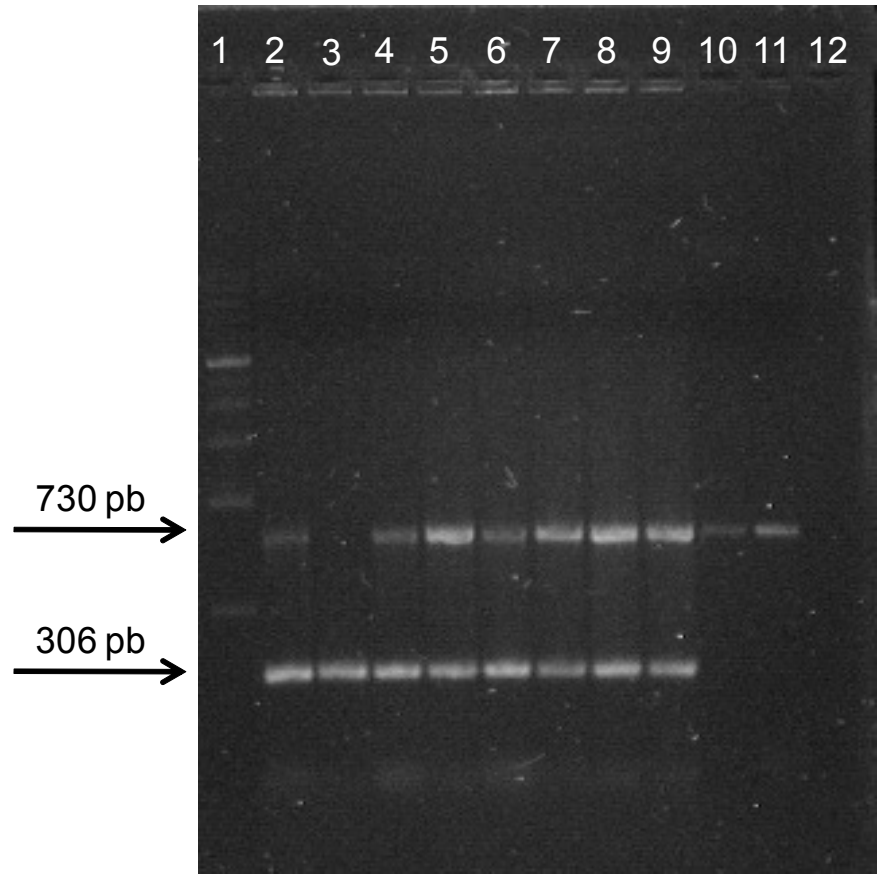

Figura 2 Análise eletroforética em gel de agarose (1\%) de $5 \mu \mathrm{L}$ dos produtos amplificados de extratos de sementes comerciais de feijão plaqueados no meio de cultura XCP1 sem antibióticos, utilizando-se os primers específicos para Xap e Cff, em uma reação multiplex. 01 marcador de DNA (Jena Bioscience); 02 Controle (Xap + Cff); 03 Lote-42; 04 Lote-29; 05 Lote36; 06 Lote-38; 07 Lote-40; 08 Lote-41; 09 Lote-47; 10 Lote-33; 11 Lote-34; 12 Lote-32.

\section{AGRADECIMENTOS}

Os autores agradecem à Fundação de Apoio à Pesquisa de Minas Gerais - FAPEMIG, pelo financiamento do projeto (CAG PPM 00531/ 09). Ao Conselho Nacional de Desenvolvimento Científico e Tecnológico - CNPq e à Coordenação de Aperfeiçoamento de Pessoal de Nível Superior - CAPES, pela concessão das bolsas de Produtividade e Pós-graduação. Aos pesquisadores que enviaram amostras de lotes de sementes e/ou grãos de feijão.

\section{REFERÊNCIAS BIBLIOGRÁFICAS}

1. Audy, P.; Laroche, A.; Saindon, G.; Huang, H.C.; Gilbertson, R.L. Detection of the bean common blight bacteria, Xanthomonas campestris pv. phaseoli and X. c. pv. phaseoli var. fuscans, using the polymerase chain reaction. Phytopathology, Saint Paul, v.84, n. 10, p. 1185-1192, 1994

2. Bianchini, A.; Maringoni, A.C.; Carneiro, S.M.T.P.G. Doenças do feijoeiro. In: Kimati, H.; Amorim, L.; Rezende, J.A.M.; Bergamin Filho, A.; Camargo, L.E.A. Manual de fitopatologia: do- 
enças das plantas cultivadas. 4. ed. São Paulo: Agronômica Ceres, 2005. v.2, cap. 37, p. 333-349.

3. Borém, A. Biotecnologia e sementes. In: Zambolim, L. Sementes: qualidade fitossanitária. Viçosa: Editora. UFV, 2005. p. 134.

4. Bragantini, C. Produção de sementes. In: Araújo, R.S.; Rava, C.; Stone, L.F.; Zimmermann, M.J.O. Cultura do feijoeiro comum no Brasil. Piracicaba: Potafos, 1996. p. 1-22.

5. Collins, M.D.; Jones, D. Reclassification of Corynebacterium flaccumfaciens, Corynebacterium betae, Corynebacterium oortii and Corynebacterium poinsettiae in the genus Corynebacterium, as Corynebacterium flaccumfaciens. Journal General of Microbiology, London, v. 129, n. 11, p. 3545-3548, 1983.

6. Deuner, C.C., Souza, R.M., Zacaroni, A.B., Figueira, A.R. Camera, J.N. Sensibilidade do método de obtenção das células bacterianas e da técnica de PCR para detecção de Curtobacterium flaccumfaciens pv. flaccumfaciens em sementes de feijão. Summa Phytopatologica, Jaboticabal, v. 38, n. 1, p.48-53, 2012.

7. Hedges, F. A bacterial wilt of the bean caused by Bacterium flaccumfaciens nov. sp. Science, Washington, v.55, n.1425, p. 433434, 1922.

8. Hedges, F. Bacterial wilt of bean (Bacterium flaccumfaciens Hedges), including comparisons with Bacterium phaseoli. Phytopathology, Saint Paul, v. 16, n.1, p.1-22, 1926.

9. Kado, C.I.; Heskett, M.G. Selective media for isolation of Agrobacterium, Corynebacterium, Erwinia, Pseudomonas and Xanthomonas. Phytopathology, Saint Paul, v. 60, n.6, p. 969-976, 1970

10. Kobayasti, L. Inoculação, transmissão e detecção por BIOPCR de Xanthomonas axonopodis pv. phaseoli em sementes de feijão. 2002. 125 f. Tese (Doutorado em Agronomia/Fitopatologia) - Universidade Federal de Lavras, Lavras.

11. Lazo, G.R.; Gabriel, D.W. Conservation of plasmid DNA sequences and pathovar identification of strains of Xanthomonas campestris. Phytopathology, Saint Paul, v.77, n.3, p. 448-453, 1987.

12. Louws, F.J.; Fulbright, D.W.; Stephens, C.T.; Bruijn, F.J. Specific genomic fingerprints of phytopathogenic Xanthomonas and Pseudomonas pathovars and strains generated with repetitive sequences and PCR. Applied and Environmental Microbiology, Washington, v. 60, n. 7, p. 2286-2295, 1994.

13. Maringoni, A.C.; Rosa, E.F. Ocorrência de Curtobacterium flaccumfaciens $p v$. flaccumfaciens em feijoeiro no Estado de São
Paulo. Summa Phytopatologica, Jaboticabal, v. 23, n. 2, p.160$162,1997$.

14. Menten, J.O.M.; Moraes, M.H.D.; Novembre, A.D.L.C.; Ito, M.A. Qualidade das sementes de feijão no Brasil. 2006. Artigo em Hypertexto. Disponível em: <http://www2.aptaregional.sp.gov.br/ artigo.php?id_artigo=404>. Acesso em: 18 mar. 2011.

15. Rego, A.M. Análise sanitária na produção de sementes de hortaliças. In: Zambolim, L. Sementes: qualidade fitossanitária. Viçosa: Editora UFV, 2005. p. 267-294.

16. Romeiro, R.S.; Perez, F.S.; Oliveira, J.R.; Peloso, M.J. Detecção de Xanthomonas campestris pv. phaseoli em sementes de feijão. Revista Brasileira de Sementes, Brasília, v.15, n.1, p. 1-5, 1993.

17. Romeiro, R.S. Métodos em bacteriologia de plantas. Viçosa: Editora UFV, 2001. v.1, 297p.

18. Sartorato, A.; Rava, C.A. Controle químico de doenças fungicas. In: Sartorato, A.; Rava, C.A. Principais doenças do feijoeiro comum e seu controle. Brasília: Serviço de produção de informação/Embrapa, 1994. p. 211-216.

19. Schaad, N.W.; Berthier-Schaad, Y.; Sechler, A.; Knorr, D. Detection of Clavibacter michiganensis subsp. sepedonicus in potato tubers by BIO-PCR and automated real-time fluorescence detection system. Plant Disease, Saint Paul, v.83, n.12, p. 1095 $1100,1999$.

20. Schaad, N.W.; Cheong, S.S.; Tamaki, S.; Hatziloukas, E.; Panopoulos, N.P. A combined biological and enzymatic amplification (BIO-PCR) technique to detect Pseudomonas syringae pv. phaseolicola in bean seed extracts. Phytopathology, Saint Paul, v.85, n.2, p. 243-248, 1995.

21. Tebaldi, N.D.; Souza, R.M.; Machado, J.C. Detecção de Xanthomonas axonopodis pv. phaseoli em sementes de feijão em meio de cultura semi-seletivo. Fitopatologia Brasileira, Brasília, v.32, n.1, p. 56-58, 2007.

22. Tegli, S.; Sereni, A.; Surico, G. PCR-based assay for the detection of Curtobacterium flaccumfaciens pv. flaccumfaciens in bean seeds. Letters in Applied Microbiology, Oxyford, v.35, n.9, p. 331-337, 2002 .

23. Toth, I.K.; Hyman, L.J.; Taylor, R.; Birch, P.R.J. PCR-based detection of Xanthomonas campestris pv. phaseoli var. fuscans in plant materials and its differentiation from X.c.pv. phaseoli. Journal of Applied Microbiology, Oxford, v.85, n.2, p. 327 $336,1998$. 